\title{
De las representaciones sociales a las representaciones étnicas y culturales: lo afrocolombiano en los medios masivos de comunicación
}

LIBERTAD TRIANA

ESTEBAN GUTIÉRREZ ${ }^{\text {I }}$

\section{Introducción}

El presente artículo aborda, desde lo descriptivo y lo explicativo, cómo se construye en la dimensión mediática expresa en los medios masivos de comunicación la representación de la dimensión cultural de ese otro que figura en la descripción de quienes en la cotidianidad llamamos negras y negros, y que por sus características físicas es diferente del "nosotros" que ha pretendido ser la sociedad mayoritaria colombiana, y transpolar dicha representación mediática en comparación con su representación histórica, a partir de la cual hacemos la lectura del pueblo afrocolombiano como sujeto histórico. En ese sentido, el ejercicio comprende un anclaje histórico-nacional, con un enfoque científico-social, orientado en el abordaje desde el campo disciplinar de la comunicación y con fines no solo académicos e investigativos sino también formativos y educativos si se quiere. Dicho en otras palabras,

1 Estudiantes de la Facultad de Comunicación Social de la Universidad Santo Tomás. 
el presente texto es el resultado de un mensurado ejercicio de investigación universitaria que imprime esfuerzos en develar nociones sobre quién es y qué ha significado el negro afrocolombiano en consideración estrecha con su dimensión cultural y étnica.

La tarea fue modesta en cuanto a unidad de análisis se refiere, se tomó como referente el repertorio de contenidos televisivos de la producción La Esclava Blanca, serie emitida por Caracol Televisión y cuya exposición a nivel nacional inició el día 26 del mes de enero del año 2016. La Esclava Blanca narra la historia ficticia del origen y recorrido de vida de una niña criolla (persona blanca e hija de españoles pero nacida en el mal llamado "nuevo continente") a quien desde la tradición europea se le nombró como Victoria Quintero. La protagonista de la historia nace el año 1821 en Santa Marta, en el seno de una reducida familia de hacendados españoles, sin embargo, con tan solo meses de nacida, los padres biológicos de Victoria fueron asesinados en un incendio provocado en la hacienda donde habitaban con la recién nacida, quien logró ser rescatada por cuenta de Lorenza, la esclava africana delegada a brindar los cuidados primarios desde el nacimiento de Victoria. Lorenza, en medio del desconcierto y el drama que dejó el incendio de la hacienda de su amo, huyó esa misma noche hacia un palenque junto con su esposo, su hija biológica y con la pequeña criolla en brazos, eventualmente es allí, en el palenque, en donde se inicia el crecimiento y la formación de Victoria como sujeto social, político, cultural y étnico, condenada a ser señalada al interior del mismo por su evidente diferenciación en la pigmentación de la piel.

Paralelo a la narración central de la protagonista, la producción seriada también narra parte de la historia, esta vez no tan ficticia, del país que era la Gran Colombia, y años después La Nueva Granada, en pleno siglo xix. En ese sentido, la producción colombiana es en esencia un reflejo nuestro en perspectiva histórica, una narración deliberada de nuestro propio contexto y de la representación que tenemos del país que fuimos hace ya casi dos centenares de años, y que a pesar de no poder negar las necesidades mercantiles a las que responden la mayor parte de producciones de carácter oficialista como ésta, que son también la justificación real de las mediaciones centradas en aspectos más sensacionales como el drama, el amor, la pasión, el engaño, 
el robo, el complot, la mentira, etcétera, -componentes del espectro de la telenovela que también nos narra, pero que no es del interés del presente artículo analizar-.

La serie sí da cuenta, a través de la pantalla chica, de un conjunto de realidades históricas que se enmarcan en la trayectoria que arrastra el proyecto de construcción del Estado Nación, y también de la construcción de las identidades colectivas e individuales que implica imaginarnos en comunión con otros muy diferentes a mí. Diremos entonces que La Esclava Blanca es la representación del país que nos imaginamos que fuimos, y en ese proceso de imaginarnos lo que fuimos, nos imaginamos también a los demás; concretamente el proyecto recae sobre los imaginarios del mundo negro, quiénes son, por qué son, dónde son, qué lugares ocupan, qué labores asumen, qué herramientas emplean y toda una mescolanza de calificativos de cara al señalamiento de los afrodescendientes colombianos que, ya no es un secreto y mucho menos tabú referirse a esto, han sido nombrados, definidos, caracterizados y moldeados socialmente por el lenguaje que impone el hombre blanco (Anderson, 1983).

Cabría partir entonces por aclarar que este no se trata de un ejercicio evaluativo o valorativo, es decir, de determinar la fidelidad, veracidad o desafinidad ni de los datos históricos de la producción seriada, ni tampoco si las representaciones que sugieren sus contenidos son acordes o no a las expresiones de una "realidad", pues bien equivocado sería pensar que, en tanto se refiera a las dimensiones sociales y culturales del ser, existen realidades objetivas.

En consonancia con las claridades anteriores, la construcción del artículo parte de la base de preguntarse ¿cuáles son los procesos de representación étnica y cultural de los sujetos y comunidades afro en el discurso propio de los medios nacionales a través de la producción televisiva La Esclava Blanca?, cuestionamiento que abarca un conjunto de aspectos que constituyen el problema de investigación; estos aspectos son: la identidad, la etnicidad, el discurso -mediático en este caso- y las representaciones.

No obstante, la construcción conceptual del problema también es una construcción en perspectiva histórica, es decir, que recae sobre las manifestaciones históricas en que se ha materializado 
fenomenológicamente el problema de investigación. Y nos referiremos a tres cuestiones concretas, acerca de las cuales recogeremos los aportes y aproximaciones de autores que, a través de textos y documentos escritos, se hayan referido respectivamente. Para efectos prácticos, nombraremos a estos tres aspectos, las tres dimensiones socio-históricas del problema, en donde hallaremos una relación causa-efecto que las articula; estas tres dimensiones son:

Primero, la dimensión de los procesos de alteridad en el marco de acontecimientos de la colonia europea sobre el "nuevo continente" habitado por otros no europeos. Al respecto Tzvetan Todorov, en su obra más canónica, La conquista de América: El problema del otro, enuncia cuáles son los aspectos que atraviesan transversalmente el asunto de la alteridad, y articula su explicación directamente con la historia del encuentro entre dos mundos tan diferentes y divergentes, en la lucha cultural, simbólica y armada por un mismo territorio (Todorov, 1987).

En segundo lugar, y como resultado de los fragmentados y alienados procesos de alteridad, una nación colombiana cuya historia se ha caracterizado necesariamente por la negación del otro. En su libro, Los indígenas colombianos y el Estado: Desafíos ideológicos y políticos de la multiculturalidad, Efraín Jaramillo Jaramillo nos relata, a través de las luchas gestadas por el Movimiento Indígena Colombiano, la forma en que estas comunidades "otras", que a pesar de hallarse cohesionadas por el territorio colombiano cuentan con un carácter étnico que desbordaba la perspectiva mestiza, buscan la reivindicación y el reconocimiento de su igualdad y diferencia frente al Estado colombiano, en un marco jurídico, legislativo y político, y frente a la sociedad mayoritaria, en un marco cultural, social y cotidiano (Jaramillo, 2011).

Por último, nuevamente como resultado de los procesos que comprenden las dimensiones ya nombradas, tenemos el ámbito de los estereotipos alrededor de la afrocolombianidad, y para abordar la cuestión apelamos, inicialmente, a la antropóloga Mara Viveros Vigoya, quien recompila todo un recorrido histórico sobre los estereotipos más y menos comunes que se han construido socialmente alrededor de las y los afrodescendientes en general, para luego aterrizar un análisis de cara a los estereotipos sobre la sexualidad y el erotismo en los afrocolombianos, en un artículo de su autoría llamado Dionisios negros: 
Estereotipos sexuales y orden racial en Colombia (Vigoya, 2010). Por otro lado, asumiendo la perspectiva del estereotipo como un imaginario propiamente, Jorge Iván Jaramillo Hincapié, en la ponencia titulada $(R e)$ presentaciones, imaginarios y estereotipos de la cuestión afrocolombiana en prensa virtual local y regional, concibe el análisis sobre el abordaje de los medios de comunicación locales y regionales sobre el espectro temático afrocolombiano (Jaramillo, 2012).

\section{Sobre el enfoque metodológico}

Los investigadores han seleccionado los diez primeros capítulos de la serie La Esclava Blanca. Con una duración aproximada de sesenta minutos cada capítulo y una composición de diez horas de material audiovisual en total, el conjunto de capítulos conforman el corpus que ha nutrido los análisis de la investigación y que nos han permitido dar respuestas a la pregunta inicial.

A la luz de las tres dimensiones del problema (alteridad en la colonia, negación de las diferencias y conformación de estereotipos), la labor se centró en la identificación de las narrativas propias del repertorio audiovisual, pero concretamente sobre aspectos semióticos del desarrollo de la narración: lenguajes (sus sentidos, significados y atributos), nombramientos, señalamientos, escalas de valor, sistemas de moralidad, relevancia e irrelevancia mediática y el discurso en general. Todo ello orientado hacia la observación sobre los aspectos temáticos que constituyan las representaciones étnicas y culturales de los afrocolombianos de la época colonial, teniendo en cuenta que el imaginario colonial que propone el medio entrará necesariamente en diálogo y conflicto con el imaginario que ya comparte, transmite y construye la sociedad colombiana contemporánea desde la tradición cultural -pensándonos la cuestión cultural desde lo que Jan Assmann concibe como memoria cultural, como parte fundamental de la memoria colectiva, en este caso de la Nación colombiana- (Assman, 1995).

Con base en los análisis discursivos del corpus seleccionado, se logró estructurar una serie de conclusiones que responden a la necesidad de identificar cuál es el lugar y el escenario social, cultural, étnico e incluso político que se le adjudica a la figura del afrocolombiano (no 
sólo como sujeto individual sino también en perspectiva de la comunidad) y, como ya se puntualizó, de la reflexión de cara a esas realidades “otras” que nos son más próximas de lo que nos sugiere en fenómeno mediático en Colombia.

\section{Análisis y conclusiones}

El abordaje de las temáticas relacionadas en el seriado parte de la existencia de una disputa política, cultural, simbólica e histórica entre dos "universos" culturales, diferentes y divergentes entre sí, propiamente nombrados en el lenguaje que emplean los personajes como el mundo del hombre blanco y, en contraposición, el mundo del hombre negro. Dos construcciones culturales que establecen códigos, valores, relaciones y habitus propios de sus cosmogonías, y que se ven expresas en dos escenarios concretos y referenciales en los capítulos analizados: Por un lado, la hacienda El Edén en la ciudad de Santa Marta, en donde rige el sistema de esclavitud replicado por la centralidad de la corona española, el hacendado es quien establece las normativas de legalidad y legitimidad, y los esclavos y esclavas se someten a las lógicas que les son impuestas al interior de dicho régimen, que se materializa en la Hacienda como el lugar propio de la construcción del hombre blanco. Por otro lado, tenemos la figura del palenque, un escenario en donde quien establece lo que se hace y deja de hacer en su interior es la comunidad afro-cimarrón, en donde rigen lógicas sustancialmente distintas desde lo organizativo, económico, político y laboral hasta lo religioso, ritual, performativo y étnico, lugar propio de la construcción del hombre negro. El choque cultural, visto sobre la primacía hegemónica de una corriente sobre la otra, nos permite evidenciar lo que en palabras de Bourdieu se concibe como una lucha simbólica que pone en juego los valores culturales de los sujetos involucrados, lucha que determina cuáles son las lógicas que más y menos “valen” en un escenario social a través de lo que propone el medio discursivamente.

Veamos, por ejemplo, cómo se expresa lo dicho anteriormente a través de la situación de Tomás, quien al iniciar el argumento de la serie es propiedad del dueño de la hacienda El Edén en su calidad de esclavo. Tomás es el ejemplo de una realidad histórica; de los esclavos 
y esclavas que, en búsqueda de la formalización de su libertad, accedían a un derecho mediante la compra del mismo, con el dinero que se hubiesen ganado al margen de sus labores como esclavos. Para los eventos iniciales de la serie, Tomás logra reunir la cantidad suficiente de dinero para, literalmente, comprar su libertad en la Hacienda El Edén, es decir, bajo las lógicas del hombre blanco. Sin embargo, luego de la fuga masiva de esclavos hacia el palenque, posterior al incendio de la Hacienda, a Tomás se le señala un nuevo camino hacia una libertad diferente, una libertad en la cual él no se proyectaba y en un marco bajo el cual nunca había concebido la idea de la libertad; la opción de ser libre en un palenque, como cimarrón, fue desaprobada por Tomás como un negro al cual se le había criado toda su vida como esclavo, él pretendía regresar a los escombros del Edén y buscar su certificado de libertad, negándose a vivir en un palenque con otros "negros rebeldes". Lo que hay aquí, discursivamente, es un esclavo que se niega a salirse de los márgenes que rigen al mundo blanco, cuya idea de libertad es la firma de un amo sobre el papel y le es desproporcional pensar que se puede ser libre sin necesidad de que el hombre blanco lo reconozca como tal bajo sus paradigmas. Para efectos de ser prácticos, diremos que para Tomás es más válido, simbólicamente, ser libre porque un hombre blanco así lo reconozca, que ser libre por fuera de los parámetros que dicta el sistema de esclavitud.

El encuentro entre los valores culturales que se demarca en el ejemplo de Tomás, nos conduce a pensar los acontecimientos de los primeros diez capítulos en la perspectiva colonial de la civilización y la barbarie. La cultura afroamericana se asocia como la de un ser primitivo y bárbaro. El blanco europeo, la civilización, lo mira como una raza inferior y por lo tanto con derecho a esclavizarlo. Sin embargo más que un problema legal o moral, la trata de esclavos fue desde el principio un problema económico.

La religión para los afrodescendientes es una representación de su cultura y por ende de su tradición ancestral, en donde prima la fuerza interior que ella les provee en su vida individual y especialmente como comunidad defensora de sus costumbres, pero también en busca de una diversidad de exigencias. Sin embargo, desde la percepción del cristianismo, la raza negra no puede considerarse como tal. Este 
conjunto de hechos logra pintar un trasfondo maniqueo de la percepción del otro donde lo negativo es negro y lo positivo blanco, al igual que configurar las mentes con esta ambivalencia. Así, se arraigaron ideologías que promueven una jerarquía entre los seres humanos y el sometimiento de los unos a los otros.

Por ejemplo, Victoria, descendiente de europeos, educada en el palenque y sin conocimiento alguno del cristianismo, es discriminada por sus compañeras palenqueras por ser blanca y por lo tanto carecer de belleza. Y aunque adopta las creencias religiosas, culturales y políticas de los afrodescendientes, al poco tiempo de recibir su tótem, se ve obligada a renunciar a su territorio para poder salvar su vida. Iniciativa del sacerdote Octavio Bocanegra, quien la envía a un convento en España. Allí tiene el deber de aprender y adoptar la vida cristiana, por lo que se ve forzada, en esta experiencia, a renunciar a sus creencias y aprender a comportarse ya no como "salvaje", sino como "civilizada". Sin embargo, ella no logra sentirse identificada con el cristianismo y permanece en la búsqueda de ideas para regresar a buscar a su familia.

Lo anterior permite hablar acerca de la configuración del espacio y las identidades. La identidad cultural siendo el rasgo preponderante de la discusión entre los grupos sociales y por supuesto, entre los territorios que habitan, ya que ella se produce y reproduce en directa relación con los espacios en los que acontece la vida social, condicionando el que aparezcan rasgos distintivos, particulares y notorios; diferenciales, en este caso, por su color de piel.

Entonces, es preciso comprender la identidad como una categoría dinámica, procesal y relacional, es decir, en constante transformación en medio de las tensiones propias de la coexistencia de la cultura afrocolombiana y eurocentrista. Esto no permite pensar a la identidad afro como estática, homogénea y cristalizada sino como una argumentación para la producción de vínculos, pero que también esa dinamicidad es expresada en las necesidades de la misma cultura.

Ahora bien, hablar de identidad, cultura y etnicidad, más allá del asunto colonial, nos obliga a tratar el tema de la alteridad. Lo primero, en este sentido, es reconocer que la cultura es un escenario de inclusión, cohesión e identificación con aspectos que evoquen sentidos específicos sobre hombres y mujeres como seres simbólicos, pero la 
cultura es también un escenario de exclusión, concebido bajo un sistema de similitud(es) y diferencia(s) que se manifiesta en la valoración y el juicio a partir del cual se cualifican a los sujetos en una matriz cultural, sea esta propia o ajena, en sintonía con lo que Todorov plantea en su obra nosotros y los otros.

Dicho lo anterior, hablar de alteridad pasa por tres componentes de un mismo asunto, también planteados por el lingüista francés, dichos componentes son: amar, conocer e identificarse; refiriéndose a tres vertientes del encuentro entre culturas distintas. Amar es el nombre que se le da al juicio moral mediante el cual nos permitimos señalar a los buenos y a los malos dentro del desarrollo de un acontecimiento, el ejemplo más claro es el caso del padre Octavio Bocanegra, a quien sus valores religiosos le conducen a ver en los esclavos seres que necesitan de su ayuda y de la gracia divina que ofrece a todo individuo el evangelio, no obstante, la relación del padre con los esclavos se limita a la benevolencia con la que un niño se dirige a un cachorro, siembre bajo la premisa de que no se encuentra en las mismas condiciones de importancia. Conocer hace referencia al acercamiento y alejamiento que la comprensión de los sistemas y modelos que rigen al otro provocan en el ser. Es a partir de este componente de alteridad que se determina la inferioridad o superioridad del otro respecto a mí, y en ese sentido, también determina mis acciones de cara al imaginario que comprendo del otro, si es necesario imponer mis valores, o someterme a los suyos, es el caso del capataz Morales, quien como pocos conocía las lógicas que regían las acciones, los pensamientos y las relaciones de los esclavos afrodescendientes, sin embargo, tener conciencia sobre dichos procesos y sus razones tampoco le fue garantía para dejar de ver en el afro un ser inferior. Identificarse es el último aspecto y el determinante en el proceso, pues es allí, en la identificación o destipificación con el otro, que se reconoce u omite la identidad del otro y de la validez de su matriz de identidad cultural o étnica.

A primera impresión, las tres cuestiones enunciadas parecen ser un listado de acciones y comportamientos que los seres humanos tomamos respecto a otros, pero para Todorov son los límites y requerimientos que aparecen en el proceso de reconocer cuál es el valor (no el precio) del otro cuyo mundo me es ajeno, para explorar las calidades 
de alteridad mediante las cuales se construyen las relaciones entre sujetos que no pertenecen a un mismo contexto cultural.

La idea anterior nos permite develar otro aspecto importante de cara a entender, grosso modo, los estereotipos más populares y reproducidos en la sociedad contemporánea. Muy bien se refleja en la novela la concepción del afrodescendiente como una mercancía carente de todo rasgo de cultura; Los negros eran objetos equivalentes a cualquier bien con valor exclusivo de uso y de cambio, es decir, los negros no valían, los negros costaban. Carentes de valor y atribuidos de precio, a los esclavos se les fue negado su pasado ancestral, sus costumbres, sus prácticas, su humanidad y, evidentemente, su libertad. Eran seres sin cultura cuyo único valor era monetario y directamente proporcional a sus capacidades corporales. Negar la existencia de unas formas y manifestaciones culturales diferentes fue negar la existencia de un ser histórico y de sus luchas de reivindicación (Jaramillo, 2011). Pensar, por ejemplo, en lo que significó el embudo cultural del mestizaje, para una amalgama de culturas como lo era -y lo es aún más hoy por hoy en una concepción más amplia de lo que cultura significa- el territorio colombiano, nos conlleva a pensar cuál es nuestro legado histórico, cómo se configura nuestra memoria cultural y con qué nos sentimos identificados, teniendo en cuenta que los valores que comparte y transmite la sociedad actual son valores importados de los procesos foráneos y ajenos, gestados en contextos muy diferentes al nuestro.

Retomando la idea que enmarca al afrodescendiente en un sistema en que su valor es proporcional a sus capacidades corporales y físicas, advertimos que los estereotipos más comunes que circulan hoy por hoy en los marcos mentales e imaginarios sociales, en torno a los sujetos afro, tienden a cosificarles y a verles como superiores a los no negros en lo que respecta a las artes del cuerpo: el sexo, el erotismo, el baile, el fisicoculturismo, los deportes, entre otros (Vigoya, 2010). Valdría la pena hacer el ejercicio de trascender esos estereotipos que cosifican a los afrodescendientes para pensarlos frente a los involucramientos con las labores contemporáneas, pues entre las imágenes más comunes que compartimos como sociedad, también está el lugar común del afro como celador, barrendero, conserje, asaltante, servidumbre, obrero, etcétera. Frente a ese mundo de los negros, que tradicionalmente se 
ha representado de la mano del discurso de los medios masivos de comunicación, surge la necesidad de dar cabida a la representación que los negros tienen de sí mismos y de las formas en que históricamente se les ha nombrado e imaginado. Al respecto, la ponencia del docente investigador Jorge Iván Jaramillo responde:

El término "negro" viene determinado por una serie de segregaciones implícitas en el imaginario colectivo social. Cómo las mismas comunidades lo mantienen latente y las determinaciones que se originan en cuanto al fenómeno. Al referirnos a la cultura afrocolombiana, la tomamos desde lo intercultural, y no en lo multicultural; pues el primero nos permite relaciones desde un adentro y desde un afuera, lo que en el multiculturalismo se presenta sólo como ese espacio donde se le da cabida a todo sin permitir lo dialógico, sin permitir la diferenciación dentro de la heterogeneidad. (Jaramillo, 2012)

Por otro lado, regresando a los escenarios en los que se hacen expresas las luchas y disputas entre regímenes culturales nombrados al inicio del análisis, tenemos que los primeros capítulos de la serie figura un palenque que significa un escenario esencial para la articulación de procesos de resistencia, ya no simplemente resistencia política, organizativa y militar, sino también de resistencia étnica y cultural. El palenque no es simplemente el lugar en donde los cimarrones están seguros de la amenaza que implica el encuentro con el hombre blanco, de ser privados de su libertad, de ser comercializados como mercancía, de ser subordinados de un "mundo" construido por blancos, sino también es el lugar dentro del cual pueden llevar a cabo sus prácticas culturales, profesar sus religiosidades y creencias, ceñirlas acorde a sus ritualidades y actor performativos y, en general, expresar todo un repertorio de narrativas culturales y de su identidad étnica ancestral, todo ello -y es así que se configura el palenque como un lugar de resistenciapor fuera del marco hegemónico que dicta el orden social de la corona española para su "nuevo continente". Ser cimarrón y palenquero significa entonces, valer por cuanto se vive y se es por fuera de las liminalidades que impone la regenta del hombre blanco. 
No obstante, y pese a todo lo anteriormente dicho sobre la construcción de una hegemonía cultural del hombre blanco sobre la negación de la cuestión afrocolombiana, señalamos un aspecto de vital importancia que devela el código en el que se inscribe la producción seriada. Es evidente, con tan solo ver un par de horas de La Esclava Blanca, que su narrativa, aunque con pretensiones anglosajonas, es sustancialmente latinoamericana y sobre las bases del género que no es tan propio, la telenovela. En un formato como la telenovela se tiende muy rápidamente a construir una estampa antagónica en la cual puedan figurar individuos desde el inicio del argumento hasta el final, en donde el antagonista paga sus pecados y delitos en la cárcel, si no es que muere antes de forma poco heroica. Pues bien, La Esclava Blanca antagoniza desde los primeros minutos al hombre blanco, con intenciones si se quiere retributivas ante la miserabilidad histórica a la que sometieron al afro por sus diferencias más que raciales, étnicas y culturales. La pregunta que cabe hacer, teniendo en cuenta un evidente impulso por hacer ver mal en un sentido moral al hombre español -y no es que neguemos o justifiquemos su leyenda negra-, sería ¿es necesario construir un concepto negativo sobre el hombre español para dar cuenta del proceso de opresión cultural del cual fueron objeto las múltiples culturas originarias, importadas y emergentes? Una pregunta para otro oportuno ejercicio de investigación.

Por último, para reflexionar la cuestión afrocolombiana en la cotidianidad de la vida contemporánea, es posible hacer un empate analógico entre la situación de la protagonista (Victoria) en el palenque y la situación de los afrodescendientes envueltos en la sociedad colombiana mayoritaria. Victoria fue una niña que, a pesar de crecer bajo la matriz cultural específica del palenque, a pesar de sentirse identificada con esas construcciones étnicas, a pesar de sentirse tan afrodescendiente como su madre, padre, hermanas y amigos, fue permanentemente rechazada por los palenqueros por la carga cultural que poseen sus condiciones físicas, su blanca piel, su lacio pelo y finas corporalidades fisionómicas. Pensar que ella representaba una minoría en el palenque nos hace ver con otro sentido las luchas sociales y de reivindicación que han tenido que gestar las comunidades afrodescendientes en su condición de minorías étnicas -y cualquier otra comunidad étnica 
diferente-, como parte de una sociedad con una herencia criolla que se basa en la exclusión del otro por sus diferencias físicas, y no en la inclusión por sus similitudes. Es decir, la situación de marginación que vive Victoria en el palenque -situación que desemboca en actos de un racismo primitivo que recae sobre las diferencias físicas y estéticas-, es la misma situación que viven los sujetos afro de cara a la sociedad colombiana, ya no solo en un dimensión palenque, sino en la ciudad, en el trabajo, en la escuela, en la universidad, en la empresa y en cualquier escenario social con el cual se vea forzoso a involucrarse.

Pensar en la dimensión cultural del afrodescendiente nos obliga a pensar un conjunto de aspectos de su identidad que, en primera instancia, ya no son necesariamente ancestrales y que dan cuenta de una serie de luchas en el campo de la comunicación como escenario estratégico para reivindicar la imagen étnica, cultural y social de las comunidades afro, y que a través de producciones como La Esclava Blanca se han ocupado de abrir nuevos espacios para dar protagonismo a nuevos sujetos que, asimismo, se empoderan y asumen, hoy por hoy, nuevos roles.

\section{Referencias}

Anderson, B. (1983). Comunidades imaginadas: reflexiones sobre en origen y la difusión del nacionalismo. Fondo de Cultura Economica, México. Recuperado de: http://www.perio.unlp.edu.ar/catedras/system/files/anderson_benedict-_comunidades_imaginadas.pdf

Assmann, J. (1995). Collective Memory and Cultural Identity. New German Critique, Duke University Press.

Bourdieu, P. (1988). Espacio social y poder simbólico. Revista Occidente. Recuperado de: https://dialnet.unirioja.es/servlet/articulo?codigo=21333

Hurtado, T. (s.f.). Los estudios contemporáneos sobre la población afrocolombiana. Recuperado de: http://www.urosario.edu.co/Subsitio/Catedra-de-Estudios-Afrocolombianos/Documentos/teodora-ER.pdf

Jaramillo, E. (2011). Los indígenas colombianos y el Estado: Desafíos ideológicos y politicos de la multiculturalidad. (Colombia), IWGIA. Recuperado de: http://www.iwgia.org/iwgia_files_publications_files/0558_libro_los_ indigenas_y_el_estado_2011_COMPLETO.pdf 
Jaramillo, J. (2012). (Re)presentaciones, imaginarios y estereotipos de la cuestión afrocolombiana en prensa virtual local y regional. Recuperado de: http://www.eafit.edu.co/centros/asia-pacifico3/Documents/PonenciasAladaa/Jaramillo_Representaciones.pdf

Todorov, T. (1987). La conquista de América: el problema del otro. Siglo veintiuno editores, Madrid, España. Recuperado de: https://gsant.files.wordpress.com/2008/01/la-conquista-de-america_todorov.pdf

Todorov, T. (1991). Nosotros y los otros. Siglo veintiuno editores, Editorial Biblioteca Nueva, México. Recuperado de: http://bibliotecanueva.es/ad$\mathrm{min} / \mathrm{links} /$ Nosostros $\% 20 \mathrm{y} \% 20 \mathrm{los} \% 20$ otros.pdf

Vigoya, M. (2010). Dionisios negros: Estereotipos sexuales y orden racial en Colombia. Recuperado de: http://lasa.international.pitt.edu/LASA98/ ViverosVigola.pdf 